\title{
O PAPEL DE ESTRUTURAS PROSÓDICAS E MORFOSSINTÁTICAS EM HIPOSSEGMENTAÇÕES DO ENSINO FUNDAMENTAL II
}

\author{
Luciani TENANI ${ }^{1}$ \\ Roberta FIEL ${ }^{2}$
}

Resumo: Neste artigo, investigamos possíveis motivações linguísticas para ocorrer hipossegmentações (como "concerteza", "jogalo") em textos escritos por alunos ao longo dos quatro últimos anos do Ensino Fundamental. Assumimos a premissa de que as hipossegmentações são resultados de relações entre fala e escrita nas quais os alunos se baseiam ao produzirem seus textos. Essas relações mobilizam, principalmente, estruturas prosódicas e morfossintáticas, além de informações letradas sobre fronteiras gráficas de palavra escrita. No que diz respeito à abordagem da prosódia, adotamos a perspectiva que a concebe como constitutiva da língua, seja falada ou escrita. Os resultados mostram que: (i) a principal regularidade prosódica é a junção de clítico mais palavra prosódica que o segue, evidenciando que a prosodização de clíticos à direita guia os registros escritos observados; (ii) a regularidade morfossintática predominante é a hipossegmentação de preposições, além de artigos, conjunções, pronomes átonos, evidenciando dificuldades na delimitação de palavras gramaticais como palavras ortográficas independentes. Quanto à distribuição de dados ao longo dos anos letivos, houve aumento de hipossegmentações que envolvem sequência de clíticos monossilábicos no nono ano, resultado que evidencia que a estrutura linguística ainda não é dominada pelos estudantes ao final do Ensino Fundamental.

Palavras-chave: Prosódia. Morfossintaxe. Ortografia. Fala. Escrita. Língua portuguesa.

\footnotetext{
${ }^{1}$ UNESP - Universidade Estadual Paulista - Departamento de Estudos Linguísticos e Literários. São José do Rio Preto - São Paulo - Brasil. 15054-000 - lutenani@ibilce.unesp.br

${ }^{2}$ UNESP - Universidade Estadual Paulista - Pós-graduação em Estudos Linguísticos. São José do Rio Preto - São Paulo - Brasil. 15054-000 - roh_fiel@ hotmail.com
}

http://dx.doi.org/10.21165/gel.v13i3.1416 


\section{Introdução}

Este artigo trata da caracterização das chamadas hipossegmentações entre palavras escritas, que são um tipo de segmentação não-convencional de palavra. Assumimos a hipótese de que, em alguma medida, a motivação dessas grafias não-convencionais da palavra está relacionada a possibilidades de organização prosódica dos enunciados falados e de construções morfossintáticas que envolvem sequências de palavras.

Com base em Capristano (2007), Cunha e Miranda (2007) e Cunha (2010) a propósito da escrita infantil, realizamos um estudo longitudinal de hipossegmentações em textos do ciclo II do Ensino Fundamental (doravante, EF II). Dessa maneira, parte da relevância desse trabalho se encontra em investigar textos escritos produzidos por alunos ao longo dos quatro anos letivos que compreende o $\mathrm{EF}^{3}{ }^{3}$, período pouco investigado quanto à segmentação de palavras, quando comparado com os estudos dessa natureza que abordam dados produzidos no período inicial de aquisição da escrita.

A partir da trajetória escrita de um conjunto de 19 sujeitos ao longo do EF II, analisamos como constituintes prosódicos (que envolvem clíticos e palavras prosódicas) e como construções morfossintáticas (sobre a configuração sintática de palavras gramaticais e lexicais) contribuem para ocorrer hipossegmentação.

Para análise dos dados, adotamos uma perspectiva sobre escrita como sendo um produto heterogêneo, constituído da relação entre os modos de enunciação falado e escrito (CORRÊA, 2001). Dessa perspectiva, relações entre fala e escrita são interpretadas a partir das relações que podem ser estabelecidas entre esses modos de enunciação e práticas orais e letradas. Nessa concepção, características do oral/falado se entrelaçam a características do letrado/escrito. Neste artigo, defendemos que esses entrelaçamentos motivam as hipossegmentações entre palavras. Assim, nos enunciados escritos estariam inscritas evidências de como esses entrelaçamentos afetam os alunos que transitam por características dos enunciados orais/falados e dos letrados/escritos.

A partir dessa concepção de escrita, assumimos a premissa de que os casos de hipossegmentações observados nos textos do EF II revelam tensões sofridas pelos alunos, pois esses têm de usar as convenções ortográficas aprendidas na escola, ao mesmo tempo

\footnotetext{
${ }^{3}$ A Lei ${ }^{\circ} 11.274$, ampliou, a partir de 2009, o Ensino Fundamental para nove anos. Assim, o EF passou a ser composto por um ano a mais em seu início e as antigas quinta, sexta, sétima, oitava séries passaram a ser nomeadas por sexto, sétimo, oitavo, nono anos, respectivamente.
} 
em que mobilizam seus conhecimentos linguísticos de falante e de escrevente em processo de formação e suas práticas orais e letradas de usos da fala e da escrita.

Nas seções seguintes, mostraremos como aspectos prosódicos dos enunciados falados e aspectos gráficos relativos às convenções ortográficas podem ser relevantes para identificação de motivações quanto à segmentação não-convencional de palavras escritas. Dessa forma, neste artigo, os objetivos são (i) descrever ocorrências (tokens) de hipossegmentações, classificá-las em tipos (types) com base em estruturas prosódicas (por exemplo, "meajude" = clítico + palavra prosódica) e morfossintáticas (por exemplo, "meajude" = pronome + verbo), e estabelecer tendências quanto aos types identificados; (ii) verificar se há correlação (ou não) de tokens e types de hipossegmentações em relação aos anos escolares.

Uma vez apresentados tema, perspectiva de análise e objetivos, passamos a tratar, a seguir, da caracterização do objeto de pesquisa, as hipossegmentações.

\section{Hipossegmentações, escrita e prosódia}

Em estudo sobre as dificuldades em segmentar palavras observadas em textos produzidos por crianças na fase inicial de contato com a escrita, Abaurre (1991) argumenta que os registros encontrados deixam entrever a interação entre critérios de natureza prosódica, sintática e semântica. Ainda de acordo com Abaurre (1991), embora os aprendizes, muitas vezes, elaborem hipóteses (inconscientemente) sobre o conceito de palavra que pode, em alguns casos, corresponder às grafias convencionais da palavra, isso não quer dizer que necessariamente os aprendizes já compartilhem dos critérios morfossintáticos e semânticos presentes na convenção ortográfica.

Somado a esse cenário no início do Ensino Fundamental, pesquisas sobre a produção escrita de alunos dos últimos anos do Ensino Fundamental têm mostrado que se mantêm os chamados erros de segmentação de palavra ortográfica (TENANI, 2010; 2009a, b, SILVA, 2014; PARANHOS, 2014), embora haja características que lhe sejam específicas. Dentre os tipos de segmentação não-convencional de palavra, este artigo delimita como objeto de estudo as chamadas hipossegmentações, que são caracterizadas pela ausência não-convencional de uma fronteira gráfica entre palavras, seja pela ausência 
do branco, como em "concerteza" (com certeza), seja pela ausência do hífen, como em "jogalo".

Neste trabalho, defendemos, baseados em Tenani (2010), Chacon (2004), Capristano (2007a, b), dentre outros, uma abordagem fonológica da prosódica que prevê que haja estruturas prosódicas e essas não estão restritas à oralidade, ou seja, são estruturas linguísticas passíveis de serem identificadas tanto em sua manifestação oral, quanto em sua manifestação escrita. Ainda segundo esses autores, a escrita é um dos modos de enunciação que se realiza por meio de práticas sociais orais e letradas, conforme propõe Corrêa (2001). Dessa maneira, adotamos uma perspectiva que assume a escrita como um produto heterogêneo por ser constituído da relação entre os modos de enunciação falado e escrito (CORRÊA, 2001). Assim, defendemos que as segmentações não-convencionais, mais especificamente as hipossegmentações, alvo de nosso estudo, são marcas privilegiadas para a observação dessa heterogeneidade, pois são marcas linguísticas de processos simbólicos que se efetivam na escrita por meio da relação com características dos enunciados orais/falados.

No que diz respeito ao objeto de análise, autores como Abaurre $(1989 ; 1991 ; 2011)$, Abaurre e Cagliari (1995), Abaurre e Silva (1993), dentre outros, têm mostrado que a presença não-convencional de espaços em branco e fatos da natureza fonética-fonológica estão intimamente ligados. Ainda para autores como Chacon (2004), Capristano (2004, 2007a, b), Tenani (2009a, b; 2010; 2011a, b), a motivação dessas grafias não-convencionais da palavra escrita está relacionada às possibilidades de organização prosódica dos enunciados falados, tais como aqueles propostos por Nespor e Vogel (1986; 2007). Neste artigo, assumimos essa perspectiva e restringimos a análise de estruturas prosódicas que possam ter motivado as hipossegmentações, amparados no modelo da Fonologia Prosódica.

De acordo com Nespor e Vogel (1986; 2007), os enunciados falados são organizados hierarquicamente em constituintes prosódicos, que são, do menor ao maior: a sílaba $(\sigma)$, o pé $(\Sigma)$, a palavra prosódica $(\omega)$, o grupo clítico $(C)$, a frase fonológica $(\phi)$, a frase entoacional (I) e o enunciado fonológico (U). Para essas autoras, esses constituintes não apresentam necessariamente isomorfia com os demais constituintes da gramática, embora possa haver coincidência entre constituintes prosódicos e sintáticos, por exemplo. Os constituintes se configuram como domínios de aplicação de processos fonológicos 
segmentais, rítmicos e, ainda, entoacionais. Neste artigo, esses domínios são vistos como estruturas organizadoras também da escrita dos alunos. ${ }^{4}$

Para a análise das hipossegmentações na escrita infantil, segundo Capristano (2007a, b) e Ticianel (2016), são mobilizados os domínios prosódicos acima da palavra prosódica na hierarquia. Dessa maneira, apresentamos, a seguir, uma breve caracterização da palavra prosódica, do grupo clítico, da frase fonológica, da frase entoacional e do enunciado fonológico.

Na hierarquia prosódica de Nespor e Vogel (1986; 2007), a palavra prosódica rotulada por palavra fonológica por Bisol (1996) - é o constituinte imediatamente acima do pé métrico, podendo ser composta por um ou mais pés. A palavra prosódica em português é caracterizada por ser portadora de um acento lexical ou acento primário (cf. BISOL, 1996). Um exemplo é a palavra "roupa", que tem um acento lexical e se constitui em uma palavra prosódica. Nesse constituinte prosódico se dá a interação entre os componentes fonológico e morfológico da gramática, não havendo necessariamente isomorfia entre as chamadas palavras prosódicas e palavras morfológicas. Um exemplo é "guarda-roupa", que se constitui em uma palavra morfológica, mas em duas palavras

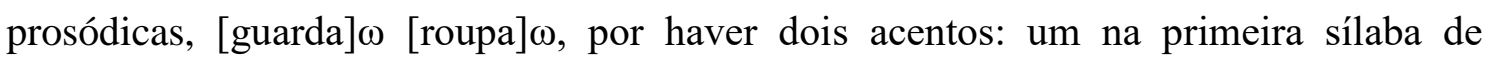
"guarda" e outro na primeira sílaba de "roupa".

A palavra prosódica é dominada pelo grupo clítico (C) que, de acordo com Bisol (2000), é formado, em português, por uma única palavra de conteúdo (hospedeiro) acompanhada de clítico prosódico, isto é, palavras desprovidas de acento lexical que correspondem principalmente a monossílabos gramaticais átonos, tais como artigos, preposições, pronomes. Exemplos da configuração desse constituinte identificados no material analisado são: "a cabeça" (artigo + substantivo), "de novo" (preposição + adjetivo), "me dar" (pronome + verbo).

Imediatamente superior ao grupo clítico configura-se a frase fonológica $(\phi)$. Esse constituinte agrupa um ou mais grupos clíticos a partir de relações de dominância sintática definidas com base no elemento nuclear de sintagmas. No corpus, a junção entre advérbio e verbo em "sempre passamos" constitui exemplo de frase fonológica, uma vez que, nesse exemplo, a relação sintática entre advérbio e verbo configura um sintagma verbal.

\footnotetext{
${ }^{4}$ Por fugir dos objetivos deste artigo, não detalharemos questões teóricas relativas à configuração da hierarquia prosódica, particularmente, no que diz respeito a problemas de recursividade e exaustividade temas amplamente debatidos na literatura sobre fonologia prosódica.
} 
O constituinte acima da frase fonológica é a frase entoacional (I) a qual se constitui a partir de orações e sentenças, mas se caracteriza, principalmente, por ser definida por contornos entoacionais. Assim, uma frase entoacional pode ser formada por um conjunto de frases fonológicas que formam orações, como em:

(1) $[$ [Ela $] \phi[$ chegou $] \phi] \mathrm{I}[$ [e deixou $] \phi[$ o livro $] \phi] \mathrm{I}$

Ou por uma frase fonológica que possua um contorno entoacional:

(2) $[$ [Cuidado! $] \phi] I$.

Por fim, o enunciado fonológico (U) é o constituinte mais alto da hierarquia prosódica que abrange relações entre frases entoacionais, como em:

(3) [ [Ela chegou]I [e deixou o livro]I ]U.

O enunciado tem sua identificação feita a partir dos limites sintáticos de sentenças e possíveis locais de ocorrência de pausa. No entanto, nem sempre o enunciado tem o mesmo tamanho do constituinte sintático sentença, podendo abranger várias sentenças em um único enunciado, como em:

(4) [ [Ela chegou.]I [Deixou o livro.]I [E foi embora calada]I ]U.

Antecipamos que, nos dados do EF II, lançaremos mão dos constituintes palavra prosódica, grupo clítico e frase fonológica, principalmente. A seguir, apresentamos a metodologia utilizada no levantamento de hipossegmentações e na classificação desses dados.

\section{Questões metodológicas}

A amostra longitudinal de textos escritos do EF II é composta de 2.495 textos produzidos por 291 alunos, dos quais 119 produziram textos em todos os anos letivos 5 . Dentre esses, 19 alunos produziram entre $100 \%$ e $95 \%$ dos textos coletados em cada ano letivo (equivalente a 25 a 26 textos/aluno). Essa subamostra é composta de 484 textos, cuja distribuição ao longo dos anos letivos permitiu um estudo longitudinal das hipossegmentações que apresentaremos a seguir. Cabe mencionar que esses textos foram escritos por alunos que cursaram os quatros últimos anos (2008 a 2011) do EF II em uma escola pública da cidade de São José do Rio Preto. O material analisado pertence ao

\footnotetext{
${ }^{5}$ Os alunos cujos textos são analisados pertencem à faixa etária de 11 a 15 anos, não havendo alunos em situação de defasagem de idade em relação ao ano escolar, pois estava em vigor a progressão continuada na rede estadual de ensino na época da coleta dos textos.
} 
Banco de Dados de Escrita do Ensino Fundamental II (TENANI, 2015), disponível gratuitamente em: 〈http://www.convenios.grupogbd.com/redacoes/Login>.

Para a identificação de registros escritos em que havia ausência de espaço entre palavras, seguimos dois critérios, a saber: (i) comparação dos espaços em branco entre palavras ao longo do texto; (ii) comparação entre as grafias das mesmas letras dentro de palavras semelhantes que ocorram no mesmo texto, conforme metodologia descrita em Tenani (2011b).

Adotamos também dois critérios de exclusão de dados, a saber: (i) exclusão de palavras homônimas, como "afim", quando previsto "a fim"; (ii) exclusão de dados de mesclas, como "pora qui” (por aqui). Esses dados se particularizam em relação aos demais registros de hipossegmentação.

O primeiro critério de exclusão foi adotado por dois motivos: (1) quantitativo, já que há muitos dados homônimos e isso gera enviesamento da amostra; e (2) morfossintático, pois casos de homonímia se particularizam em relação aos demais dados: a uma mesma cadeia fônica correspondem duas grafias, porque são duas as palavras morfológicas na língua. É o critério morfossemântico que garante a escolha de uma e não de outra forma ortográfica, como em “enfrente" e "em frente". É interessante mencionar que, na coleta de dados, foram encontradas 56 palavras homônimas (p.e. "agente" - "a gente", "ensima" - “em cima"). Os dados de "agente" são os mais recorrentes (49 ocorrências) dentre as palavras homônimas. Esse conjunto de dados será objeto de futuras pesquisas.

O segundo critério relativo à exclusão das mesclas justifica-se por esse tipo de dado envolver tanto a hipossegmentação (ausência não-convencional de fronteira gráfica entre "por" e "aqui”) quanto a hipersegmentação (presença não-convencional de fronteira gráfica dentro de "a qui"). Esses dados são considerados um terceiro tipo de ocorrência de segmentação não-convencional de palavra, merecendo um estudo específico.

Por fim, para a classificação das hipossegmentações, foi adotado um critério gráfico por meio do qual se classifica o dado em: (i) ausência não-convencional do branco, como em "dinovo" (“de novo"); (ii) ausência não-convencional do hífen, como em "matalo" ("matá-lo"). Essa distinção é importante em função de os contextos de emprego do hífen serem restritos em relação ao branco, além de o hífen ter natureza 
distinta em relação ao branco quanto à delimitação de fronteira de palavra: enquanto o branco sempre delimita palavras, o hífen tanto as delimita, quanto as une.

Na próxima seção, descrevemos as características morfossintáticas e prosódicas dos dados de hipossegmentação levantados.

\section{Hipossegmentações no EF II}

Dos 484 textos pertencentes à amostra longitudinal, identificamos um total de 164 hipossegmentações pela ausência não-convencional da fronteira gráfica, sendo 152 por ausência do branco e 12 pela ausência não-convencional do hífen. Dentre os 152 dados por ausência de branco, 56 são casos de homonímia que foram excluídos desta análise. Portanto, neste trabalho, faremos a análise de 108 hipossegmentações, sendo 96 pela ausência do branco e 12 pela ausência do hífen.

Com base em Tenani e Fiel (no prelo), esses dados, produzidos por 19 sujeitos, foram considerados em relação ao número de palavras que produziram em seus textos de modo a ser obtido índice de frequência de hipossegmentação. Entre os 19 alunos, a taxa é de 0,22 de hipossegmentações/palavras escritas. Abaixo, apresentamos gráfico de índice de hipossegmentação de cada sujeito da pesquisa. Como informado na seção anterior, o índice foi obtido a partir da divisão da quantidade total de dados (tokens) pelo total de palavras escritas por aluno. No eixo horizontal, identifica-se cada aluno por número ${ }^{6}$ atribuído aleatoriamente no banco de dados de onde foram selecionados.

\footnotetext{
${ }^{6}$ A atribuição de número aos sujeitos da pesquisa visou a garantir a proteção da identidade dos alunos, assegurando-se, assim, o cumprimento de critérios éticos em pesquisa.
} 


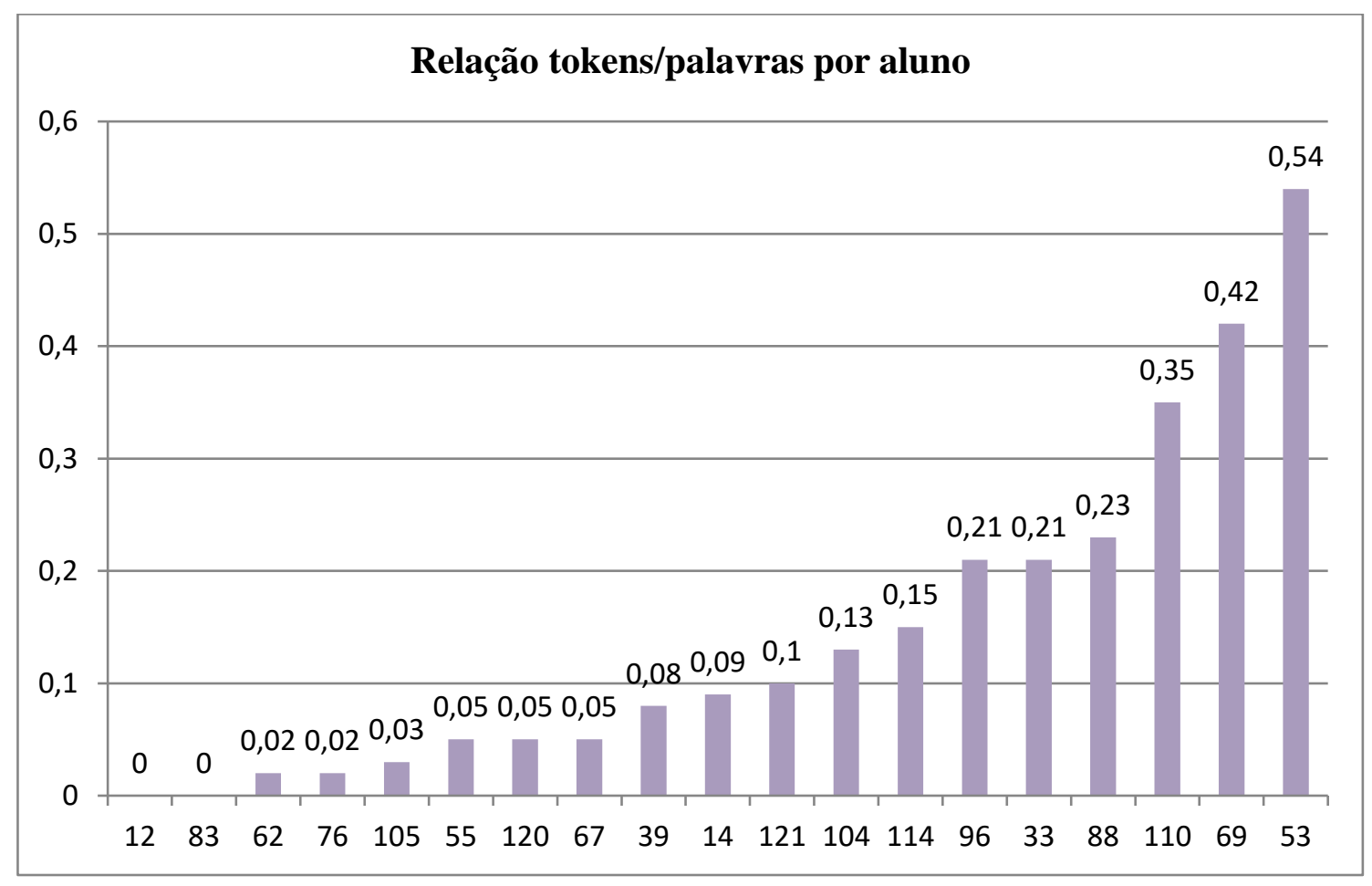

Gráfico 1 - Relação tokens de hipossegmentação/palavras escritas por aluno

A partir do gráfico acima, podemos agrupar os sujeitos em quatro conjuntos:

(i) Dois alunos não tiveram casos de hipossegmentação;

(ii) Oito alunos tiveram taxa menor que 0,10 de ocorrências;

(iii) Cinco alunos produziram de 0,10 a 0,21 de ocorrências, estando abaixo da média do grupo analisado;

(iv) Quatro alunos apresentaram frequência de hipossegmentação acima da média do grupo: o primeiro muito próximo da média, com 0,23 , e os demais acima, sendo o segundo com 0,35 , o terceiro com 0,42 e o quarto com 0,54 .

Desse levantamento, conclui-se que a maioria dos alunos $(89,47 \%)$ possui dados de hipossegmentação e somente três dos 19 alunos $(15,78 \%)$ podem ter seus textos classificados com índices de segmentação de palavra muito acima dos verificados para seus pares. Esses resultados sugerem que a maioria dos alunos escreve conforme as convenções ortográficas, como esperado por se tratarem de alunos do EF II, e apenas três desses alunos poderiam ser classificados com disortografia, um distúrbio específico de escrita (cf. FERNANDÉZ et alii., 2010), se baseados no critério de segmentação de palavra. Afastam-nos dessa visão que concebe os chamados erros de segmentação de palavra como índice de disortografia para nos aproximar de uma perspectiva que concebe 
essas grafias como índices do trânsito do sujeito escrevente por práticas orais/faladas e letradas/escritas e, portanto, passíveis de análise linguística que identifica nessas grafias regularidades acerca dos usos das palavras. No entanto, não descartamos um estudo de caso desses alunos com mais altos índices de hipossegmentação. Esse estudo, porém, não será feito aqui.

Avançamos na descrição dos dados de modo geral a partir da investigação da relação types/tokens de hipossegmentação para cada sujeito. No gráfico que se segue, visualiza-se essa relação.

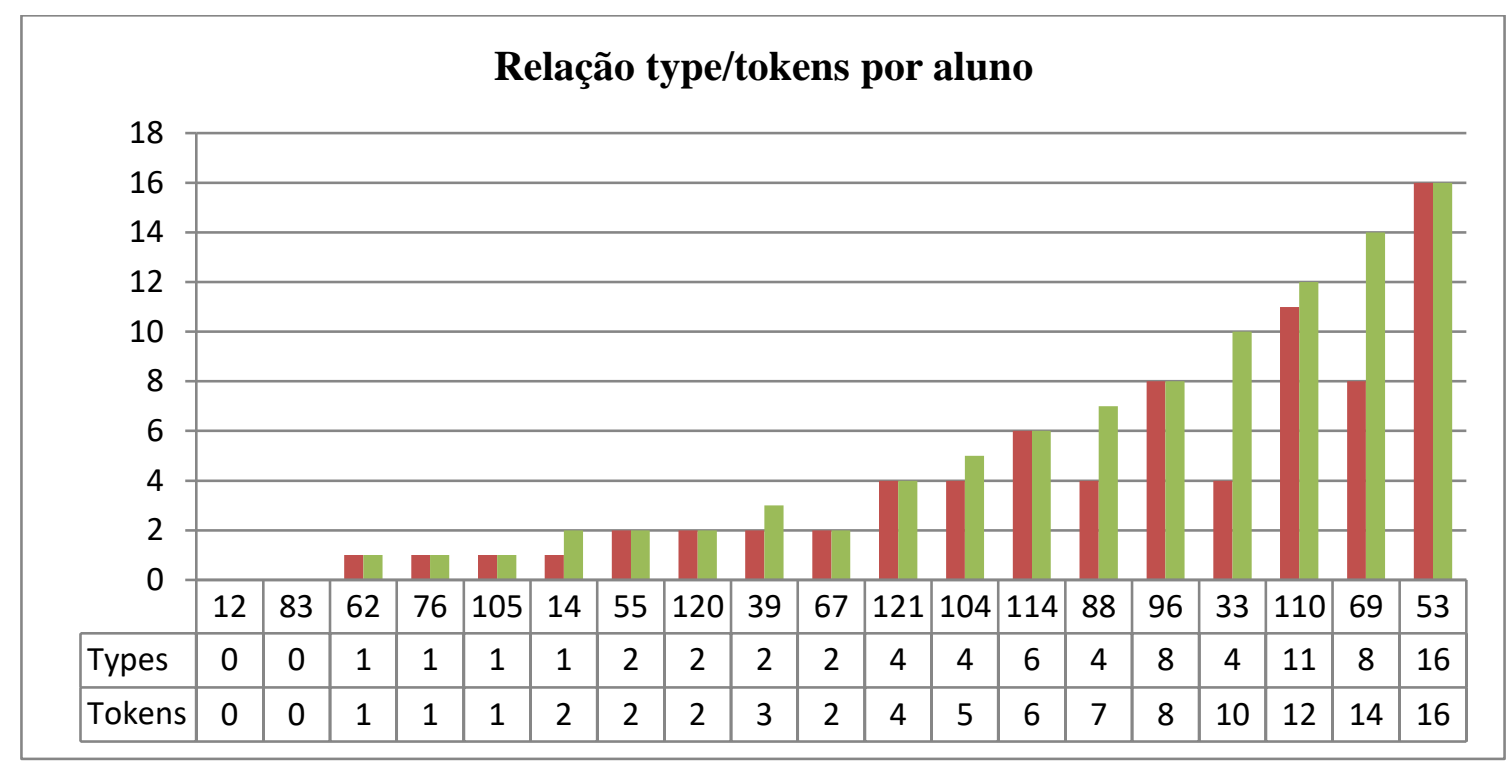

Gráfico 2 - Relação type/token de 19 alunos

No gráfico 2, observamos que a diferença entre o número de tokens em relação ao número de types é pequena para a maioria dos alunos. Somente para dados de três alunos, a saber: 88,33 e $69^{7}$, há diferença de mais de dois pontos entre o número de ocorrências (tokens) e o número de palavras morfológicas (types). Esse resultado quantitativo vai em direção distinta daquele observado por Silva (2014) para dados longitudinais de hipersegmentações (presença não-convencional de fronteira gráfica) identificadas em textos desse mesmo banco. Segundo essa autora, os escreventes produziram muitas ocorrências de hipersegmentação que se deram a partir das mesmas palavras. Observamos que, no caso das hipossegmentações, as dificuldades não se localizam,

\footnotetext{
${ }^{7}$ Desses três alunos, apenas o 69 também apresentou alto índice de hipossegmentação.
} 
predominantemente, em palavras específicas, embora possa ser estabelecido um conjunto de poucas sequências de palavras sobre as quais os alunos mostraram ter mais dificuldade em segmentar, a saber: “o que”, 18 vezes $(18,75 \%)$; “de repente”, 4 vezes $(4,17 \%)$; “de novo", 5 vezes $(5,21 \%)$.

Feita essas considerações gerais, passamos à descrição da classificação das 108 hipossegmentações de acordo com critérios gráficos de fronteira de palavra.

\section{Hipossegmentações no EF II: características gráficas}

Dois grupos de dados foram definidos de acordo com a ausência do recurso gráfico que marca fronteira de palavra: (i) a ausência não-convencional do branco, (ii) ausência não-convencional do hífen. A partir dessa classificação, identificamos o número de dados em cada ano letivo e também calculamos: (i) porcentagem de hipossegmentação em relação ao total de ocorrências e (ii) índice de ocorrência de hipossegmentação em cada ano letivo, a fim de obter uma medida relativa da ocorrência de hipossegmentação em relação ao total de palavras escritas. Na tabela (1), são apresentados os dados quantitativos obtidos.

\begin{tabular}{crrrrrr}
\hline Ano letivo & \multicolumn{2}{c}{$\begin{array}{r}\text { Recurso gráfico } \\
\text { Branco }\end{array}$} & $\begin{array}{r}\text { Hífen } \\
\text { Hipossegmentação } \\
\mathrm{N}^{\mathbf{0}}\end{array}$ & $\begin{array}{r}\text { Palavras } \\
\mathrm{N}^{\mathbf{0}}\end{array}$ & Hipo/palavra \\
\hline $\mathbf{6}^{\mathbf{0}}$ & 18 & 3 & 21 & 19,44 & 13.887 & 0,15 \\
$\mathbf{7}^{\mathbf{0}}$ & 34 & 1 & 35 & 32,41 & 19.012 & 0,18 \\
$\mathbf{8}^{\mathbf{0}}$ & 17 & 4 & 21 & 19,44 & 14.799 & 0,14 \\
$\mathbf{9}^{\mathbf{0}}$ & 27 & 4 & 31 & 28,70 & 25.705 & 0,12 \\
Total & 96 & 12 & 108 & 100,00 & 73.403 & 0,15 \\
\hline
\end{tabular}

Tabela 1 - Ocorrências de hipossegmentação por critério gráfico e ano letivo

$\mathrm{Na}$ tabela (1), observa-se ligeiro decréscimo do índice de ocorrência de hipossegmentação em função do aumento do tempo de escolarização: no sexto ano, o índice foi de 0,15 enquanto no nono ano, 0,12. A exceção é o índice de 0,18 do sétimo ano, que se constitui no maior índice apurado. Quando excluídos os dados por hífen, os índices obtidos da relação entre hipossegmentação e número de palavras escritas são semelhantes aos índices totais. Portanto, independentemente do tipo de recurso gráfico ausente nas hipossegmentações, faz-se necessário aprofundar a análise dos dados do 
sétimo ano a fim de verificar possíveis fatores que possam estar favorecendo a presença de hipossegmentações no material considerado. Os resultados obtidos, porém, apontam para o maior domínio das convenções ortográficas pelos alunos que concluem o EF, embora esse domínio não seja completo, pois ainda foi constatada hipossegmentação (no nono ano houve $28,7 \%$ do total de dados, sendo as porcentagens menores no oitavo e sexto anos).

Sobre hipossegmentações pela ausência do hífen, há ocorrências em todos os anos, porém há ligeiro aumento nos dois últimos anos do EF. Todos os 12 dados coletados se tratam de estruturas enclíticas, por exemplo, "derrotalos" (“derrota-los"), "matalo" ("mata-lo"), o que revela dificuldades dos alunos investigados com esse tipo de estrutura. Esse tipo de hipossegmentação por ausência de hífen é similar ao encontrado por Cunha (2010) em textos do EF I. Segundo essa autora, os casos de ênclise, como "chamace" (“chama-se"), ocorrem em menor quantidade, pois essa colocação pronominal não é a mais comum na fala do português brasileiro, fato que pode servir como mais uma motivação para que os escreventes representem, na escrita, essa sequência como uma única palavra.

Cabe comentar que, além dessas 12 hipossegmentações com estruturas enclíticas, outras 12 ocorrências com uso não-convencional do hífen foram observadas na coleta de dados. São estruturas nas quais os alunos usam hífen entre palavras que convencionalmente não o recebem, como em "não-se", "voltar-lá". Embora esse tipo de dado não seja, a rigor, caso de hipossegmentação, mas de uso não-convencional de hífen, é interessante observar que essas palavras, em sua maioria, configuram possíveis estruturas enclíticas da língua. Esses usos não-convencionais do hífen ocorrem no decorrer dos quatro anos do EF II, porém são em maior número no último ano (5/12).

Esse resultado quanto ao aumento de usos não-convencionais do hífen pode ser reflexo de práticas letradas mais institucionalizadas (CORRÊA, 2004), já que a ênclise é ensinada e, sobretudo, valorizada na escola. Essa valorização de colocação pronominal enclítica aparece indiciada nos dados desses alunos na medida em que a escrita nãoconvencional pode ser interpretada como tentativa de alçamento do aluno à escrita valorizada socialmente (por exemplo: escola, universidade). ${ }^{8}$

\footnotetext{
${ }^{8}$ Os alunos que participaram desta pesquisa sabiam que seus textos seriam lidos por professores da UNESP (cf. TENANI; LONGHIN-THOMAZI, 2014).
} 
Dessa forma, com base em Corrêa (2004), interpretamos que essas estruturas dão indícios do imaginário social do escrevente sobre o que é escrita (mais especificamente sobre o que é o código escrito institucionalizado). Esse imaginário, de acordo com esse autor, é construído pela inserção do escrevente nos mais diversos usos formais e informais da língua(gem).

Lembramos, junto com Tenani (2011b), que o uso do hífen evidencia o processo de letramento pelo qual os escreventes transitam, uma vez que os contextos em que esse recurso gráfico ocorre de maneira não-convencional se constituem em estruturas associadas a produções escritas mais formais e institucionalizadas. Dessa forma, nossa hipótese explicativa é a de que esses usos não-convencionais do hífen em estruturas enclíticas identificados no córpus revelem que o escrevente estaria tentando alçar estruturas típicas de enunciados escritos valorizados socialmente, ensinadas justamente nos dois últimos anos do EF.

\section{Hipossegmentações no EF II: características morfossintáticas}

No que diz respeito às configurações morfossintáticas das 96 hipossegmentações por branco, foram identificadas quatro possibilidades de junção, a saber: palavra gramatical e lexical; palavra lexical e gramatical; sequência de duas palavras gramaticais; e sequência de duas palavras lexicais, como exemplificado, na Tabela 2. Em todas as ocorrências, houve junção entre apenas duas palavras ortográficas, resultado relevante, porque particulariza esses dados do EF II em comparação com textos infantis, nos quais há junções que envolvem três ou mais palavras, como "quermipega" para "quer me pegar" (TICIANEL, 2016, p. 114), além de junções entre duas palavras.

\begin{tabular}{lllrrrrrrr}
\hline Tipo & Sequências de & Exemplo & \multicolumn{3}{c}{ Hipo x Ano escolar } & \multicolumn{2}{c}{ Total } \\
\cline { 3 - 9 } & palavras & de Hipo & $6^{\mathbf{o}}$ & $7^{\mathbf{0}}$ & $8^{\mathbf{o}}$ & $9^{\mathbf{0}}$ & $\mathrm{n}^{\mathbf{o}}$ & $\%$ \\
$\mathbf{1}$ & gramatical + lexical & "anoite" & 13 & 19 & 13 & 7 & 52 & $54,17 \%$ \\
$\mathbf{2}$ & gramatical + gramatical & "oque" & 2 & 4 & 2 & 17 & 25 & $26,04 \%$ \\
$\mathbf{3}$ & lexical + gramatical & "temque" & 1 & 7 & 1 & 3 & 12 & $12,50 \%$ \\
$\mathbf{4}$ & lexical + lexical & "seila" & 2 & 4 & 1 & 0 & 7 & $7,29 \%$ \\
Total & & & 18 & 34 & 17 & 27 & 96 & $100 \%$ \\
\hline
\end{tabular}

Tabela 2 - Classificação de hipossegmentação em sequências de palavras por ano escolar 
$\mathrm{Na}$ Tabela 2, a maior porcentagem de dados, com 54,17\% do total (52/96), é resultante da junção de uma palavra gramatical mais uma palavra lexical (tipo 1), como em "acabeça" (“a cabeça") e "aspessoas" (“as pessoas"). A segunda estrutura que mais ocorre com 26,04\% (25/96) é a junção de duas palavras gramaticais (tipo 2), como em “edo" ("e do"), "oque” (“o que”). Um menor conjunto de dados compreende a junção de uma palavra lexical mais uma palavra gramatical (tipo 3) com 12,50\% (12/96) dos dados, como em "temque" ("tem que") e "alende" ("além de"). Da comparação entre as sequências de tipo (1) e (3), verifica-se a tendência geral de hipossegmentação da palavra gramatical quando seguida por lexical, em todos os anos letivos, exceto no nono ano, quando há mais ocorrências do tipo (2). Já a junção de duas palavras lexicais (tipo 4) representa o menor conjunto de dados, com baixa ocorrência em todos os anos letivos, totalizando 7,29\% das hipossegmentações (7/96), como "semprepassamos" ("sempre passamos"), "tabom" (“está bom"). Em cada um desses tipos de sequências, contatamos que as palavras hipossegmentadas pertencem a diferentes classes gramaticais, como exemplificado na Tabela 3.

Tabela 3 - Classificação morfossintática de hipossegmentações por ano letivo

\begin{tabular}{cccccccrr}
\hline Tipo & Classe de palavra & Exemplo & \multicolumn{3}{c}{ Hipo/ano escolar } & \multicolumn{2}{c}{ Total } \\
& & & $6^{\mathbf{0}}$ & $7^{\mathbf{0}}$ & $8^{\mathbf{o}}$ & $9^{\mathbf{0}}$ & $\mathrm{n}^{\mathbf{o}}$ & $\%$ \\
\hline $\mathbf{1}$ & Artigo + Subst. & "acabeça" & 1 & 2 & 2 & 1 & 6 & 6,25 \\
& Artigo + Verbo & "apegou" & 1 & 0 & 0 & 0 & 1 & 1,04 \\
& Prep. + Subst. & "denoite" & 5 & 9 & 6 & 3 & 23 & 23,96 \\
& Prep.+ Adj & "denovo" & 1 & 1 & 1 & 2 & 5 & 5,21 \\
& Prep./artigo + & "afrente" & 1 & 0 & 0 & 1 & 2 & 2,08 \\
& Subst. & & & & & & & \\
& Prep. + Adv. & "poraqui" & 2 & 3 & 2 & 0 & 7 & 7,29 \\
& Prep./artigo + Adv. & "pelomenos" & 0 & 1 & 1 & 0 & 2 & 2,08 \\
& Pronome + Verbo & "midar" (me dar) & 1 & 2 & 1 & 0 & 4 & 4,17 \\
& Pronome + Subst. & "nostodos" & 1 & 0 & 0 & 0 & 1 & 1,04 \\
& Conj. + verbo & "etenho" & 0 & 1 & 0 & 0 & 1 & 1,04 \\
\hline $\mathbf{2}$ & Artigo + Pronome & "oque" & 1 & 3 & 1 & 15 & 20 & 20,83 \\
& Conj. + prep./artigo & "edo" (e do) & 0 & 0 & 1 & 0 & 1 & 1,04 \\
& Prep. + Pronome & "porisso" & 0 & 1 & 0 & 2 & 3 & 3,13 \\
& Pronome + & "queu" (que eu) & 1 & 0 & 0 & 0 & 1 & 1,04 \\
& Pronome & & & & & & & \\
\hline $\mathbf{3}$ & Subst. + Pronome & "bemdela" & 0 & 0 & 0 & 1 & 1 & 1,04 \\
& Subst. + Prep. & "fautade" & 0 & 0 & 1 & 0 & 1 & 1,04 \\
& & & & & & & (continua)
\end{tabular}


(continuação)

\begin{tabular}{|c|c|c|c|c|c|c|c|c|}
\hline & Adv. + Prep. & "lem" (lá em) & 0 & 4 & 0 & 0 & 4 & 4,17 \\
\hline & Verbo + Artigo & "vio" & 0 & 1 & 0 & 0 & 1 & 1,04 \\
\hline & Verbo + Prep. & "enportapara" & 0 & 0 & 0 & 1 & 1 & 1,04 \\
\hline & Verbo + Pronome & "tenque" & 0 & 2 & 0 & 1 & 3 & 3,13 \\
\hline & Adj. + Prep. & "alende" & 1 & 0 & 0 & 0 & 1 & 1,04 \\
\hline 4 & Verbo + Adj. & "tabom" & 1 & 2 & 0 & 0 & 3 & 3,13 \\
\hline & Verbo + Verbo & "toindo" & 0 & 1 & 0 & 0 & 1 & 1,04 \\
\hline & Adv. + Subst. & "befeito" & 1 & 0 & 0 & 0 & 1 & 1,04 \\
\hline & Adj. + Subst. & "tomundo" & 0 & 1 & 0 & 0 & 1 & 1,04 \\
\hline & Adv. + Verbo. & "semprepassamos" & 0 & 0 & 1 & 0 & 1 & 1,04 \\
\hline & & & 18 & 34 & 17 & 27 & 96 & 100,0 \\
\hline
\end{tabular}

A constatação de que todas as classes de palavras estão envolvidas em hipossegmentações em todos os anos letivos poderia levar à suposição de que: (i) classe de palavras não seria característica relevante para identificar motivação para a hipossegmentação no EF II, e/ou (ii) os anos de escolarização não proporcionam domínio das convenções ortográficas da língua materna dos alunos estudados. No entanto, dentre as estruturas listadas na tabela 3, ocorreu com mais frequência a junção entre preposição e substantivo com 23,96\% (23/96), como em "encasa" (“em casa") e "denoite" (“de noite"). Se somadas todas as junções que envolvem preposições, independentemente da classe gramatical da palavra a que se junta, sobe para 43,75\% (42/96) as ocorrências, o que sinaliza maior dificuldade dos alunos em grafar preposições monossilábicas. Esse resultado sugere a necessidade de análise aprofundada das estruturas morfossintáticas envolvidas na hipossegmentação a fim de investigar possíveis motivações que podem ser de naturezas distintas, a saber: (i) quantitativa, na medida em que haveria mais preposições entre os monossílabos empregados nos textos escritos e, assim, as junções de preposições são apenas efeitos de frequência; ou (ii) qualitativa, na medida em que preposições são palavras gramaticais com funcionamento complexo (cf. ILARI, 2015), o que proporcionaria maior dificuldade no seu emprego por alunos no EF. Portanto, o resultado descrito aponta para possíveis desenvolvimentos de pesquisas que considerem fatores morfossintáticos a fim de confirmar ou refutar o que aqui se acena como motivo para a manutenção de hipossegmentação no EF II.

O segundo maior conjunto de dados identificados compreende o tipo (2), predominantemente, "oque", cujas ocorrências aumentam no último ano do EF. Esse 
resultado, por ser diferentemente do esperado, levou-nos a observar grande flutuação entre grafia convencional e não-convencional em um mesmo texto, havendo dados de diferentes alunos, sugerindo que possa haver alguma motivação linguística nessa flutuação, hipótese a ser investigada. Também em textos do EF I, Ticianel (2016) identificou tendência em hipossegmentação de "oque", como: "oque vocês faz a hora do recreio". Nos textos infantis, essas hipossegmentações dizem respeito a enunciados interrogativos, predominantemente. Nos dados do EF II, apenas uma grafia "oque" ocorreu em enunciado interrogativo ${ }^{9}$, sendo a maioria dessas hipossegmentações de outra natureza. Esse resultado particulariza os dados do EF II em relação ao EF I e, ao mesmo tempo, aponta para um necessário estudo específico dos usos e grafias de "o que" nos textos infanto-juvenis.

Ainda é importante observar que parte das ocorrências que envolvem palavra prosódica e clítico (tipo 3) poderia ser interpretada como evidência de emergência de gramaticalização de construções morfossintáticas, como é o caso de construções com “tem que” (BARROS, 2012). A análise desse tipo de hipossegmentação implica, portanto, considerar complexidade morfossintática de construções de junção de orações, inclusive aspectos de mudanças gramaticais em curso no português, o que não está no escopo deste artigo, mas está no horizonte de nossas pesquisas. Esse resultado sinaliza, ao lado dos arrolados anteriormente, a complexidade morfossintática envolvida na hipossegmentação de palavras, não podendo esses dados serem vistos como simples interferência da fala na escrita.

No caso de ausência de hífen, $100 \%$ dos 12 dados são junção de uma palavra lexical mais palavra gramatical. Todos os dados são estruturas enclíticas compostas por verbos mais pronomes, como em "pegala" (pega-la) "testalo" ("testa-lo"). Esse resultado em dados longitudinais é semelhante ao descrito por Tenani (2011b) para dados transversais. Neste estudo longitudinal, verificamos que esse tipo de grafia se distribui ao longo dos anos do EF II, o que indicia a manutenção de problemas no aprendizado do registro escrito de ênclise verbal. Portanto, identificou-se que os alunos não aprendem as convenções ortográficas de estruturas morfossintáticas específicas, como a ênclise verbal.

\footnotetext{
${ }^{9}$ A única grafia de "oque" em enunciado interrogativo em texto do EF II ocorreu em contexto de discurso direto de fala de personagem: "Foi então que o homem chegou fazendo enorme pampeiro, gritando: oh! Meu senhor oque aconteceu com meus olhos, não vejo mais nada, me ajude senhor!" (Fonte: Texto Z11_8B_15F_04).
} 
Os resultados mostram ainda que alunos do EF II continuam com dificuldade em segmentar palavras gramaticais constituídas de uma sílaba como preposições, artigos, conjunções, pronomes. Esse tipo de registro também é o que mais oferece dificuldades aos alunos do EF I (CUNHA, 2010).

\section{Hipossegmentações no EF II: Características prosódicas}

No que concerne às características prosódicas das hipossegmentações, identificamos cinco estruturas prosódicas, sendo, em ordem decrescente de frequência de ocorrências: (i) clítico seguido de palavra prosódica; (ii) sequência de dois clíticos; (iii) sequência de duas palavras prosódicas; (iv) sequência de palavra prosódica e clítico; e (v) sequência de dois clíticos que se configuram em frase fonológica. Na tabela a seguir, além de exemplos, são apresentados os números de ocorrências ao longo dos anos letivos.

\begin{tabular}{ccccccccc}
\hline Tipo & \multirow{2}{*}{ Estrutura } & Exemplo de Hipo & \multicolumn{3}{c}{ Hiper/ano escolar } & \multicolumn{2}{c}{ Total } \\
\cline { 3 - 8 } & & & $5^{\mathrm{a}}$ & $6^{\mathrm{a}}$ & $7^{\mathrm{a}}$ & $8^{\mathrm{a}}$ & $\mathrm{n}^{\mathbf{o}}$ & $\%$ \\
$\mathbf{1}$ & $\mathrm{cl}+\omega>\mathrm{C}$ & acabeça & 12 & 19 & 11 & 9 & 51 & $52,58 \%$ \\
$\mathbf{2}$ & $\mathrm{cl}+\mathrm{cl}>\omega$ & oque & 2 & 3 & 2 & 14 & 21 & $21,65 \%$ \\
$\mathbf{3}$ & $\omega+\omega>\phi$ & semprepassamos & 3 & 5 & 3 & 2 & 13 & $13,40 \%$ \\
$\mathbf{4}$ & $\omega+\mathrm{cl}>\mathrm{C}$ & fautade & 1 & 7 & 1 & 1 & 10 & $10,31 \%$ \\
$\mathbf{5}$ & $\mathrm{cl}+\mathrm{cl}>\phi$ & oque & 0 & 0 & 0 & 1 & 1 & $1,03 \%$ \\
& & & 18 & 34 & 17 & 26 & 96 & $98,97 \%$ \\
\hline
\end{tabular}

Tabela 4 - Estruturas prosódicas de hipossegmentação

Quanto à frequência de ocorrências, constatamos que pouco mais da metade dos dados, totalizando 52,58\% (51/96), é junção de um clítico (cl) mais uma palavra prosódica $(\omega)$, constituindo um grupo clítico, como exemplificado na Tabela 4. Esse tipo de estrutura apresenta pouco decréscimo de incidência ao longo dos anos letivos (passa de $12,50 \%$ no sexto ano para $9,38 \%$ no nono ano), embora, no último ano, continue sendo a segunda estrutura mais frequente, com 9,38\% (9/96) dos dados, enquanto a estrutura mais frequente nesse ano letivo passa a ser a sequência de clíticos, com 14,58\% (14/96).

De modo geral, a junção de dois clíticos é o segundo tipo de estrutura mais recorrente com 21,65\% (21/96), originando uma palavra prosódica, “oque”, pois o segundo elemento clítico passa a ser hospedeiro do primeiro nas ocorrências 
identificadas. Essa frequência deve-se, sobretudo, à quantidade de dados identificadas no último ano letivo como observado na seção anterior: saltou de duas a três ocorrências em cada um dos três primeiros anos letivos para 14 ocorrências no nono ano. Essa distribuição chama a atenção não apenas pelo aumento não esperado, mas especificamente por envolver basicamente o registro "oque". Reiteramos que esse resultado carece de investigação futura, com objetivo de descrever o estatuto de "o que" em textos do EF, tendo por fundamento as descrições e análises sintáticas feitas sobre o português brasileiro.

Outros dois conjuntos de dados, com frequências próximas entre si, compreende a junção de duas palavras prosódicas, com 13,40\% (13/96) dos dados, e a junção de uma palavra fonológica e um clítico, com 10,31\% (10/96). Essas duas estruturas apresentam poucos dados em cada ano letivo, sendo que ambas têm maior frequência no sétimo ano, resultado que vislumbramos investigar futuramente, pois é possível, por hipótese, que haja fatores relacionados aos tipos de gêneros textuais propostos nesse ano letivo que tenham favorecido esses tipos de registros.

Quanto à natureza prosódica desses dois tipos de junções, cabe observar que são estruturas bastante diferentes entre si. A junção entre palavras prosódicas leva à configuração de frase fonológica, como em "semprepassamos", porém também há registros como "tábom" que, embora seja, a princípio, duas palavras prosódicas, pode ser interpretado, como fez Paranhos (2014), como sequência de clítico e palavra prosódica, pois formas verbais reduzidas como "tá" perdem o acento lexical e funcionam, em enunciados falados, como clíticos prosódicos. Já a junção entre palavra prosódica e clítico, como "tenque", constitui estrutura enclítica, pouco comum no português brasileiro que tem a característica principal de próclise, como "denovo". Esse tipo de junção compreende, também, sequências que se configuram a partir de processos de gramaticalização, como observado na seção anterior.

O último tipo de estrutura prosódica ocorreu somente uma vez no córpus analisado $(1,03 \%)$. Trata-se de uma ocorrência de dois clíticos que, de um ponto de vista sintático, funcionam como um sintagma dentro de um enunciado interrogativo (cf. nota 7) o que nos leva a interpretá-lo como uma frase fonológica, a semelhança do que foi feito por Ticianel (2016) em dados de escrita infantil. 
De modo geral, os resultados descritos permitem afirmar que alunos do EF II tendem a juntar um monossílabo átono com a palavra que lhe segue, evidência de direção da prosodização de clíticos em português brasileiro. Demais estruturas identificadas carecem de estudo mais aprofundado sobre relação entre estruturas prosódicas e construções morfossintáticas da língua. Neste artigo, descrevemos quatro estruturas prosódicas presentes em textos do EF II que envolvem os constituintes palavra prosódica, grupo clítico e frase fonológica. Esse resultado caracteriza os dados de hipossegmentação do EF II quando comparados com os dados de EF I, pois nessa etapa inicial da escrita também estão envolvidos os constituintes de frase entoacional e enunciado fonológico.

\section{Considerações finais}

Neste artigo, foi feita descrição de tendências de características prosódicas morfossintáticas de hipossegmentações presentes em amostra longitudinal de textos do EF II. Os resultados descritos permitiram estabelecer duas tendências principais sobre a hipossegmentação do EF II:

(i) ocorrem hipossegmentações em todos os anos do EF II, com um aumento no nono ano de junção de clíticos como "oque";

(ii) predominam hipossegmentações de preposições, artigos, conjunções, pronomes que se constituem em clíticos monossilábicos e ocorrem, em sua maioria, em posição proclítica à palavra lexical, hospedeiro do clítico prosódico.

Por fim, concluímos que essa pesquisa contribui com os estudos sobre a escrita do EF II à semelhança do que já vêm sendo realizado por Tenani (2009a, 2010, 2011b), Silva (2014) e outros. Vale ressaltar que a importância em se investigar dados do EF II pode ser justificada não apenas em função dos poucos estudos realizados, mas, principalmente, como afirmado por Silva (2014), por já ser esperado do escrevente, nesse período de escolarização, a produção de textos "com domínio da separação em palavras" (PCN, 1997, p. 80). Mostramos, que, ao contrário do esperado, os alunos continuam a ter dificuldades em reconhecer os limites de palavra escrita, especialmente de palavras gramaticais monossilábicas, mesmo já tendo terminado, em termos formais, o período de alfabetização. A descrição prosódica e morfossintática realizada permitiu uma caracterização geral das hipossegmentações e contribuiu para sinalizar que tipos de 
estruturas linguísticas oferecem mais dificuldades aos alunos do EF II no processo de produção de textos escritos, apontando, assim, caminhos para futuras pesquisas sobre o tema.

Agradecimentos: Agradecemos ao CNPq, pelas bolsas de Produtividade em Pesquisa (CNPq 309872/2012-0) e bolsa PIBIC (Proc. 2014/29329) e à FAPESP pela concessão de auxílio à pesquisa (Proc. 2013/14546-5).

TENANI, Luciani; FIEL, Roberta. The role of the prosodic and morphosyntactic structures in word hyposegmentations from junior high school. Revista do Gel, São Paulo, v. 13, n. 3, p. 107-129, 2016.

Abstract: In this article, we investigate possible linguistic motivations to occur word hyposegmentations (such as "concerteza," "jogalo") in texts written by students over the last four years of Junior High School. We assume that hyposegmentations are results of relations between speech and writing from which students base their writing. These relations mainly concern the prosodic and morphosyntactic structures, besides literate information about written word graphic boundaries. With regard to the approach of prosody, we adopt the perspective that conceives it as constitutive of language, either spoken or written modality. The results show that: (i) the main prosodic regularity is the junction of a clitic plus a prosodic word that follows it, which shows that the right direction of clitics prosodization guides the observed written spellings; (ii) the predominant morphosyntactic regularity is the hyposegmentation of prepositions, followed by articles, conjunctions, unstressed pronouns, which are the evidence of the student's difficulties in recognizing grammatical words as independent written words. As the statistics over the school years, we also found that there is an increase of hyposegmentations involving clitic monosyllabic sequences in the ninth year, a result that reflects that the linguistic structure is not yet mastered by students at the end of Junior High School.

Keywords: Prosody. Morphosyntax. Spelling. Orality. Literacy. Portuguese language.

Submetido em: 07/04/2016.

Aceito em: 22/06/2016. 


\section{Referências}

ABAURRE, M. B. M. Hipóteses iniciais de escrita: evidências da percepção, pela criança, de unidades rítmico-entonacionais na fala. In: IV Encontro Nacional da ANPOLL, 1989, Recife. Anais do IV Encontro Nacional da ANPOLL. Recife: UFPE, 1989. p. 751-764.

A relevância dos critérios prosódicos e semânticos na elaboração de hipóteses sobre segmentação na escrita inicial. Boletim da Abralin, Campinas, v. 11, p. 203-217, 1991.

A relação entre escrita espontânea e representações linguísticas subjacentes. Verba Volant, Pelotas, v. 2, p. 167-200, 2011.

ABAURRE, M. B. M.; CAGLIARI, L. C. Textos espontâneos na primeira série: evidências da utilização, pela criança, de sua percepção fonética da fala para segmentar a escrita. Jornal da Alfabetizadora, v. 9, 1995.

ABAURRE, M. B. M.; SILVA, A. O desenvolvimento de critérios de segmentação na escrita. Temas em psicologia. São Paulo, v. 1, p. 89-102, 1993.

BARROS, E. C. M. Construções modais com "ter": gramaticalização e variação. 2012. 246 f. Tese (Doutorado em Linguística) - Faculdade de Letras, Universidade Federal do Rio de Janeiro, Rio de Janeiro, 2012.

BISOL, L. O clítico e seu status prosódico. Revista de Estudos da Linguagem, Belo Horizonte, v. 9, n.1, p. 5-20, 2000.

Constituintes prosódicos. In: BISOL, L. Introdução a estudos de Fonologia do português brasileiro. Porto Alegre: EDIPUCRS, 1996. p. 247-261.

BRASIL. Secretaria de Educação Fundamental. Parâmetros Curriculares Nacionais: língua portuguesa. Brasília: 1997.

CAPRISTANO, C. C. Mudanças na trajetória da criança em direção à palavra escrita. 2007. 263 f. Tese (Doutorado em Linguística Aplicada) - Instituto de Estudos da Linguagem, Universidade Estadual de Campinas, Campinas, 2007a.

Aspectos de segmentação na escrita infantil. São Paulo: Martins Fontes, 2007b.

A propósito da escrita infantil: uma reflexão sobre as segmentações nãoconvencionais. Letras de Hoje, Porto Alegre, v. 39, n. 3, p. 245-260, 2004.

CHACON, L. Constituintes prosódicos e letramento em segmentações nãoconvencionais. Letras de Hoje, Porto Alegre, v. 39, n. 3, p. 223-232, 2004.

CORREA, M. L. G. O modo heterogêneo de constituição da escrita. São Paulo: Martins Fontes, 2001. 
CUNHA, A. P. N. As segmentações não-convencionais da escrita inicial: uma discussão do ritmo linguístico do português brasileiro e europeu. 2010. 188 f. Tese (Doutorado em Educação) - Faculdade de Educação, Universidade Federal de Pelotas, Pelotas, 2010.

CUNHA, A. P. N.; MIRANDA, A. R. M. A influência da hierarquia prosódica em hipossegmentações da escrita de crianças de séries iniciais. Revista Virtual de Estudos da Linguagem, Porto Alegre, v. 1, p. 1-19, 2007.

FERNÁNDEZ, A. Y.; MÉRIDA, J. F. C.; CUNHA, V. L. O.; BATISITA, A. O.; CAPELLINI, S. A. Avaliação e intervenção da disortografia baseada na semiologia dos erros: revisão da literatura. Revista CEFAC, São Paulo, v. 12, n. 3, p. 499-504, 2010. Disponível em: <http://www.revistacefac.com.br/fasciculo.php?form=edicoes/v12n3.php $>$ Acesso em: 05 jul. 2013.

FERREIRO, E.; PONTECORVO, C. Os limites entre as palavras: a segmentação em palavras gráficas. In: FERREIRO, E. et alii. Chapeuzinho Vermelho aprende a escrever. São Paulo: Ática, 1996. p. 38-77.

ILARI, R. (Org.). Gramática do português culto falado no Brasil: palavras de classe fechada. São Paulo: Contexto, FAPESP, 2015.

NESPOR, M.; VOGEL, I. Prosodic phonology. Dordrechet: Foris Publications, 1986.

NESPOR, M.; VOGEL, I. Prosodic phonology: with a new foreword. Berlin; New York: Mouton de Gruyter. 2007.

PARANHOS, F. C. Segmentações não-convencionais de palavra nos quatro últimos anos do ensino fundamental: um estudo longitudinal. 2014. 169 f. Dissertação (Mestrado em Estudos Linguísticos) - Instituto de Biociências, Letras e Ciências Exatas, Universidade Estadual Paulista, São José do Rio Preto, 2014.

SILVA, L. M. Um estudo longitudinal sobre as hipersegmentações de palavras escritas nos anos finais do ensino fundamental. 2014. $171 \mathrm{f}$. Dissertação (Mestrado em Estudos Linguísticos) - Instituto de Biociências, Letras e Ciências Exatas, Universidade Estadual Paulista, São José do Rio Preto, 2014.

TENANI, L. Entre o grupo clítico e a palavra fonológica: os erros de segmentação nãoconvencional de palavras. VI Congresso Internacional da ABRALIN, 2009a.

A segmentação não-convencional de palavras: evidências de representações de relações entre enunciados falados e escritos. Anais do II SIMELP: língua portuguesa: ultrapassar fronteiras, juntar culturas, 2009b. p. 107-127.

A segmentação não-convencional de palavras e a aquisição da escrita. Palestra apresentada no II Ciclo de Palestras sobre aquisição da linguagem e escrita. Faculdade de Educação, Universidade Federal de Pelotas, Pelotas. 2010. 
Letramento e segmentações não-convencionais de palavras. In: TFOUNI, L. Letramento, escrita e leitura: questões contemporâneas. Campinas: Mercado das Letras, 2011a.

A segmentação não-convencional de palavras em textos do ciclo II do ensino fundamental. Revista da ABRALIN, v. 10, p. 91-119, 2011 b.

Banco de Dados de Escrita do Ensino Fundamental II. Disponível em: <http://www.convenios.grupogbd.com/redacoes/Login>. Acesso em: 22 fev. 2016.

TENANI, L.; FIEL, R. Hipersegmentação de palavras em textos do EFII: características prosódicas gerais. Linguasagem, São Carlos. No prelo.

TENANI, L.; LONGHIN-THOMAZI, S. Oficinas de leitura, interpretação e produção textual no ensino fundamental. Em Extensão. Universidade Federal de Uberlândia, Uberlândia, v. 13, n. 1, 2014.

TICIANEL, G. F. Discurso direto e hipossegmentações na aquisição da escrita. 2016. 193 f. Dissertação (Mestrado em Letras) - Centro de Ciências Humanas, Letras e Artes, Estadual de Maringá, Maringá, 2016. 